Original Article

\title{
A predictive model of anxiety and depression symptoms after a lower limb amputation
}

\author{
Susana Pedras, M.D. ${ }^{\text {a }}{ }^{*}$, Rui Carvalho, M.D. ${ }^{b}$, M. Graça Pereira, Ph.D. ${ }^{a}$ \\ a School of Psychology, Applied Psychology Department, University of Minho, Campus Gualtar, 4710-057 Braga, Portugal \\ b Division of Endocrinology, Diabetes and Metabolism, Centro Hospitalar do Porto, Largo Prof. Abel Salazar, 4099-001 Porto, Portugal
}

\section{A R T I C L E I N F O}

\section{Article history:}

Received 12 October 2016

Received in revised form

15 March 2017

Accepted 22 March 2017

\section{Keywords:}

Anxiety

Depression

Diabetic Foot Ulcer

Amputation

Pre-surgery

Post- surgery

\begin{abstract}
A B S T R A C T
Background: Patients with Diabetic Foot Ulcer (DFU) show high levels of depression and anxiety symptoms. The loss of a limb is undoubtedly a devastating experience and several studies have shown that anxiety and depression symptoms are a common reaction after a lower limb amputation (LLA). However, no study has focused on the immediate emotional reactions to LLA as a personal factor based on the ICF Model.

Objective: This study focused on the characterization of anxiety and depression levels, before and after surgery, differences in levels of depression and anxiety before and after surgery and the predictors of anxiety and depression one month after surgery, in a sample of patients with DFU.

Methods: This was a longitudinal study with 179 patients with Diabetes Mellitus Type 2 and DFU indicated for amputation, screened for the presence of anxiety and depression symptoms during the hospitalization that preceded amputation and one month after surgery, during a follow-up consultation.

Results: The results showed a significant effect of anxiety and depression symptoms at pre-surgery in the prediction of anxiety and depression symptoms one month after LLA. Patients showed higher levels of anxiety than depression symptoms at pre-surgery, although anxiety significantly decreased on month after surgery. Both anxiety and depression symptoms contributed to depression after LLA, although anxiety at pre-surgery was the only predictor of anxiety at post-surgery.

Conclusions: Tailored multidisciplinary interventions need to be developed providing support before and after an amputation surgery, in order to reduce anxiety and depression symptoms and promote psychological adjustment to limb loss.
\end{abstract}

(c) 2017 Elsevier Inc. All rights reserved.
Anxiety and depression symptoms in patients with Diabetes are substantially higher than in the general population ${ }^{1}$ and, in the presence of Diabetes complications, like Diabetic Foot Ulcer (DFU), several studies have reported the negative contribution of high levels of anxiety and depression to poor disease outcomes. ${ }^{2-5}$ Empirical evidence suggests that this relationship is bidirectional. On the one hand, anxiety and depression are particularly harmful to self-care behaviors and have been associated with poorer diabetes control, poor adherence to medication, diet and to foot self-care behaviors $^{6-11}$ whereas, on the other hand, DFU requires several daily self-care behaviors and treatments that may precipitate the

\footnotetext{
* Corresponding author.

E-mail addresses: susanapedras@gmail.com (S. Pedras),rui.morais.carvalho@ gmail.com (R. Carvalho), gracep@psi.uminho.pt (M.G. Pereira).
}

onset of, or even trigger, depression and anxiety symptoms. ${ }^{12-14}$ Depression has also been reported to be associated with larger and more severe foot ulcers, a higher risk of nonhealing and recurrent foot ulcers during follow-up. ${ }^{14-16}$

Regarding anxiety symptoms, existing data are not as clear as with depression. Tennvall and Apelqvist ${ }^{17}$ reported that patients with a history of healed ulcers presented less anxiety symptoms than patients with an existing ulcer. In turn, Carrington et al. ${ }^{18}$ did not find any differences in the levels of anxiety in patients with foot ulcers when compared with amputee patients. However, recently, in a study with a large population sample of adults, a relationship between anxiety disorders and an increased risk of ulcers over a 10year period was reported. ${ }^{19}$ Also, anxiety and depression symptoms are commonly interwoven imposing similar risks and intensifying poor medical outcomes. ${ }^{1,20,21}$ 
In addition, studies have revealed that patients, prior to surgery, presented high levels of pre-surgery anxiety. Pre-surgery anxiety, although a normal part of the surgical experience, is a generalized problem that triggers a physiological stress response which may hinder the healing process. ${ }^{22}$ In fact, anxiety in surgical patients may increase the need for higher levels of anaesthesia, resulting in possible anaesthetic risk, post-surgery pain and medication requirements, which can greatly affect postsurgery recovery. ${ }^{23}$ Anxiety also plays a significant role in increasing the risk of infection and decreasing immune system response. ${ }^{24}$ Therefore, anxiety and depression symptoms should not only be seen as common reactions to a surgery but, as symptoms that may have adverse effects in post surgery if not assessed and adequately intervened.

According to the Portuguese Diabetes Society, in Portugal, in 2014 there were 560 major and 825 minor lower limb amputations (LLA) related to $\mathrm{DFU}^{25}$ which is a major health problem for the health care system and for society, given these patients' needs for continuous health care and social reintegration.

In patients already amputated, the loss of a limb is undoubtedly a devastating experience, and several studies have shown that anxiety and depression symptoms are a common reaction, ${ }^{26-30}$ which may be present for up to six weeks after amputation. ${ }^{29,31,32}$ Regarding anxiety symptoms, in a Portuguese sample, about $36 \%$ of 45 amputee patients showed symptoms of anxiety clinically significant and 39\% symptoms of depression clinically significant after LLA (less than 6 months). ${ }^{33}$ Studies regarding postsurgery anxiety have revealed that anxiety symptoms were related to fears of pain and loss of physical functioning and mobility, to negative effects of surgery on body image, as well as fears associated with the return to a normal daily routine (daily tasks and roles) and concerns about future social and professional problems. ${ }^{34,35}$

Furthermore, patients with DFU may also experience acute pain during wound care when dressings are changed, and/or chronic pain as a result of arterial insufficiency (Peripheral Arterial Disease, PAD), infection, osteomyelitis and/or (painful) neuropathy. ${ }^{36}$ Moreover, pain is reported in the literature as interfering significantly with all areas of patient functioning, ${ }^{37}$ although being underestimated by health professionals. ${ }^{38}$ In addition, anxiety and depression symptoms are positively associated with pain severity. ${ }^{39}$ However, it still remains unclear whether pain causes anxiety and depression symptoms or whether psychological symptoms precipitate and/or enhance pain. Despite the nature of this relationship, pain is actually a well-known predictor of depression in patients with leg ulcers, having a deleterious effect on post-surgery wound healing ${ }^{40}$ and, more frequently, contributing to delays in wound healing in patients with elevated levels of anxiety. ${ }^{41}$

The International Classification of Functioning, Disability and Health (ICF) of the World Health Organization, ${ }^{42}$ is a classification system that describes the consequences of illness and disability. This conceptual model emphasizes the role that personal and environmental factors play in the functioning and capabilities of an individual with a health condition. However, the ICF model is not clear on how these personal factors influence adjustment to disability and, in the present case, regarding adjustment to LLA. In an attempt to improve the understanding regarding the early predictors of emotional reactions to amputation and how they may contribute to adjustment to LLA, this study focused on the dynamic interaction between a medical condition (lower limb amputation) and personal factors (emotional reactions). Results will provide an opportunity, based on empirical findings, to manage and contribute to change personal factors in order to provide adequate psychological and social support for patients following LLA. ${ }^{43,44}$
The majority of studies have focused on the presence of anxiety and depression symptoms at pre-surgery or at long term after LLA, yet have failed to assess those symptoms at postsurgery, and to study the contribution of pre-surgery symptoms to post-surgery symptoms. As the systematic review by Horgan and MacLachlan ${ }^{45}$ has shown, studies of psychological morbidity have neglected the immediate psychological reaction to LLA. In fact, no study, to our knowledge, has explored the prevalence of anxiety and depression symptoms one month after surgery, when patients are immediately confronted with the limitations and constraints caused by limb loss, given that this period may be essential for stump cicatrisation and for the adjustment to limb loss. Thus, it is fundamental to understand the prevalence of anxiety and depression symptoms in this population, whether there are differences in anxiety and depression symptoms from pre-surgery to post-surgery, and which pre-surgery variables contribute to post-surgery anxiety and depression symptoms. The results will allow the design of policies and the development of evidence-based interventions, that address the specific needs of patients with DFU during the rehabilitation program immediately after LLA.

\section{Methods}

\section{Participants and procedure}

A sample of 179 patients with Diabetes Mellitus Type 2 (DMT2) and DFU indicated for amputation surgery was screened for the presence of anxiety and depression symptoms during the hospitalization that preceded LLA, and was assessed during a follow-up consultation at the hospital, approximately one month after surgery (mean 34.98 days). The mean duration of length of hospital stay was 25 days. Socio-demographic and clinical data were extracted from patient's medical charts by health professionals (nurses and physicians).

This study has a longitudinal design with two moments of assessment: pre-surgery (T0) and post-surgery (T1). Between T0 and T1, 66 patients withdrew leaving a sample of 113 patients for the final analysis (experimental mortality was $36.8 \%$ ). The causes for withdrawal and exclusion were: 29 surgeries were cancelled, 18 did not have a follow-up vascular or diabetic foot consultation, 6 refused to participate in the T1 assessment, 5 died, 3 did not attend the follow-up vascular or diabetic foot consultation, 3 could not collaborate due to their mental state (showed cognitive impairment after surgery) and 2 involved post surgical complications and hospitalization in another hospital. These 66 patients did not differ from the remaining 113 patients in terms of baseline characteristics (gender, age, previous amputations, type of foot, diabetes duration, history of previous ulcer and amputations). Therefore, this sample included patients that had already had a LLA and patients that were indicated for their first LLA. The amputation was secondary to diabetic neuropathy and/ or peripheral arterial disease. The study was conducted between June 2013 and April 2015 in six hospitals at the Diabetic Foot Multidisciplinary Clinics and two Vascular Surgery Departments in the North of Portugal where the rate of LLAs is the lowest in the country. ${ }^{25}$ Assessment interviews were face-to-face and made by a health psychologist. Inclusion criteria were: having DMT2 and DFU, be indicated for LLA, be more than 18 years old and not presenting any diagnosed psychiatric disorder.

Ethical approval was obtained by the hospital ethics committee and all participants were previously informed about the study. Participation was voluntary and involved the signing of an informed consent form. 


\section{Measures}

Socio Demographic Questionnaire that included questions on age, education level, marital and professional status and the presence of a caregiver.

Clinical Data Questionnaire included questions concerning the onset of diabetes duration of diagnosis, history of previous ulcer and amputation, length of inpatient stay, number of complications related to diabetes (nephropathy, retinopathy, neuropathy and peripheral arterial disease), type of foot, presence of pain and other chronic diseases and psychiatric/psychotropic medicine intake. Type of foot was defined as neuropathic or neuroischemic according to ulcer aetiology.

Hospital Anxiety and Depression Scale (HADS). ${ }^{46,47}$ This scale assesses depression and anxiety symptoms on a 14-item scale: 7 items for anxiety and 7 items for depression. The item response format is a Likert scale ranging from 0 to 3, with scores ranging from between 0 and 21. Higher scores indicate higher levels of anxiety and depression respectively. In the current sample, internal consistency reliability was adequate for both anxiety $(\alpha=0.86)$ and depression $(\alpha=0.88)$ scales. To characterize the levels of anxiety and depression in the study, a score of 11 or higher indicates probable presence ("caseness") of a mood disorder, i.e., symptoms clinically significant, using the Portuguese validation of HADS. ${ }^{47}$ This instrument is a widely used measure in clinical practice in hospital settings, assessing depression and anxiety symptoms and a brief, relatively quick and easily administered instrument, that has shown good psychometric properties and which has been validated in Portuguese patients with diabetes ${ }^{47}$ and in amputees. ${ }^{48}$

\section{Statistical analysis}

Analyses were conducted using SPSS version 22. Continuous variables are presented either as mean, standard deviation and range $(\mathrm{min} / \mathrm{max})$, whereas dichotomous data are presented as numeric and percentage. The prevalence of symptoms clinically significant of anxiety and depression at T0 and T1 was estimated using the authors' cut off scores ( $>11$ ). In order to analyse whether differences in anxiety and depression depended on clinical and socio demographic variables, a repeated measures analysis of variance was performed with the number of amputations, ulcer duration and length of hospital stay, as covariates. The covariates were chosen taking into account their correlation with the dependent variables and their relevance in the literature. Finally, a multiple hierarchical regression model (method enter) was used to find the predictors of anxiety and depression symptoms, in T1. The variables included in the model were those that showed a significant correlation with each of the dependent variable in previous bivariate associations and relevance according to the literature. In the first block, socio demographic and clinical variables were included (gender, age, type of foot, number of hospitalizations and complications, presence/absence pain) and, in the second block, the psychological variables (baseline depression and anxiety). To control for multicollinearity, the variance inflation factor value (VIF) was established at below 2 and the tolerance coefficient was set to be greater than 0.60 .

\section{Results}

\section{Sample characterization}

At baseline (T0), 179 patients with DFU participated in the study. Of these, seventy-six had already been amputated $(23.7 \%$ and $76.3 \%$ major and minor LLAs, respectively), and 113 patients participated in the second moment of the assessment (T1) approximately one month after surgery (22.1\% and $77.9 \%$ major and minor LLAs, respectively). Other sample socio demographic and clinical variables are presented in Table 1.

\section{Incidence of anxiety and depression symptoms at T0 and T1}

Based on the HADS, there was evidence of high levels of anxiety and depression symptoms indicating the probable presence ("caseness") of a mood disorder. Regarding anxiety symptoms, $63.7 \%$ (95\% confidence interval $=54.9-72.6 \%)$ and $41.6 \%(95 \%$ confidence interval $=32.7-52.5 \%$ ) of patients exceeded the HADS cut-off score of 11 at T0 and T1 respectively, presenting symptoms clinically significant. Regarding depression symptoms, 42.5\% (95\% confidence interval $=32.8-52.5 \%)$ and $46.9 \%$ of patients $(95 \%$ confidence interval $=38.1-55.8 \%$ ) exceeded the HADS cut-off score of 11 at T0 and T1 respectively, presenting symptoms clinically significant.

\section{Differences in anxiety and depression symptoms from TO to T1}

Multivariate analysis of repeated measures showed that there were significant differences regarding anxiety and depression from pre to post-surgery, (Wilk's Lambda $=0.08, F(2,108)=4.67$, $p=0.011$ ), controlling the number of previous amputations, ulcer duration and length of hospital stay which were introduced as covariates. Also, univariate results showed that time had a significant effect but only for anxiety, $F(1,100)=4.76, p=0.031$, i.e.

Table 1

Sample socio demographic and clinical characteristics at T0 $(\mathrm{N}=179)$.

\begin{tabular}{|c|c|c|c|c|}
\hline Continuous measures & Min & Max & Mean & SD \\
\hline Age & 36 & 90 & 66.4 & 11.03 \\
\hline Education level (years) & 0 & 17 & 4.65 & 3.08 \\
\hline Duration diabetes diagnosis (months/years) & 1 & $636 / 53$ & 221.9 & 138.9 \\
\hline History of previous ulcer (months/years) & 1 & $264 / 22$ & 45.33 & 57.79 \\
\hline Duration of ulcer (weeks) & 1 & 192 & 18.86 & 23.66 \\
\hline Number of complications & 1 & 4 & 3.01 & 0.96 \\
\hline Length of inpatient stay (days) & 3 & 80 & 25.9 & 14.9 \\
\hline Categorical measures & $\mathrm{n}$ & & & $\%$ \\
\hline \multicolumn{5}{|l|}{ Gender } \\
\hline Female & 52 & & & 29.1 \\
\hline Male & 127 & & & 70.9 \\
\hline \multicolumn{5}{|l|}{ Professional Status } \\
\hline Employed & 14 & & & 7.8 \\
\hline Unemployed & 21 & & & 11.7 \\
\hline Sick leave & 11 & & & 6.1 \\
\hline Retired & 133 & & & 74.3 \\
\hline \multicolumn{5}{|l|}{ Marital Status } \\
\hline Married or Cohabitant & 119 & & & 66.5 \\
\hline Widow/single/divorced & 60 & & & 33.5 \\
\hline \multicolumn{5}{|l|}{ Caregiver } \\
\hline No & 23 & & & 12.8 \\
\hline Yes & 156 & & & 87.2 \\
\hline \multicolumn{5}{|l|}{ Type of foot } \\
\hline Neuroischemic & 134 & & & 74.9 \\
\hline Neuropathic & 45 & & & 25.1 \\
\hline \multicolumn{5}{|l|}{ 1st Amputation } \\
\hline Yes & 103 & & & 57.5 \\
\hline No & 76 & & & 42.5 \\
\hline \multicolumn{5}{|l|}{ Psychiatric medicines intake } \\
\hline Yes & 60 & & & 33.5 \\
\hline No & 119 & & & 66.5 \\
\hline \multicolumn{5}{|l|}{ Presence of pain } \\
\hline Yes & 111 & & & 62 \\
\hline No & 68 & & & 38 \\
\hline \multicolumn{5}{|l|}{ Presence of other chronic disease } \\
\hline Yes & 39 & & & 21.8 \\
\hline No & 140 & & & 78.2 \\
\hline
\end{tabular}


anxiety symptoms decreased from $\mathrm{T} 0$ to $\mathrm{T} 1$, however there were no significant differences in depression symptoms, $F(1,100)=1.99$, $p=0.161$.

\section{Predictors of depression and anxiety symptoms at T1}

The multiple regression analysis showed that, in step 1, demographic and clinical characteristics explained $10 \%$ of the variance of depression symptoms at T1, with age being a significant positive predictor. In the final model, only anxiety and depression symptoms at $\mathrm{T} 0$ were the significant predictors of depression at $\mathrm{T} 1$, since age was no longer a significant predictor. The final model explained $24 \%$ of the variance $\left(\operatorname{adj} R^{2}=0.24, p<0.001\right) F(8,104)=5.44$, $p<0.001$. Table 2 displays results of the regression model.

Anxiety symptoms at T1 were predicted only by anxiety at T0. None of the clinical and socio demographic variables were significant predictors. The final regression model was significant and explained $21 \%$ of the variance (adj $R^{2}=0.21, p<0.001$ ) $F(8,104)=4.77, p<0.001$. Please see Table 2 .

\section{Discussion}

The aims of this study were to assess and characterize the level of anxiety and depression symptoms in a sample of patients with DFU indicated for LLA at T0 and at T1, and which pre-surgery variables contribute to post-surgery anxiety and depression given that knowing the pre-surgery predictors of post-surgery emotional reactions would allow the development and implementation of preventive programs to support and promote positive clinical outcomes, in this population. According to results, prior to surgery, patients showed a higher level of anxiety compared to depression symptoms clinically significant. This result may be related not only with premorbid anxiety and depression levels, but also with the fears and tension associated with surgery that, in turn, increases premorbid levels of anxiety. Apart from the fear of surgery (not waking up after surgery, etc), along with the fear of a change in body image, it is understandable that patients experience more symptoms of anxiety than depression at T0. In fact, the number of patients with depression symptoms increased from T0 (42.5\%) to T1 (46.9\%). Regarding anxiety symptoms, they decreased from T0 (63.7\%) to T1 (41.6\%). Taking into account the small sample size, these results are alarmingly high. Therefore, the comparison among the studies is not appropriate due to the differences in sample sizes. However, the prevalence of depression and anxiety symptoms in our sample remains very close to other studies such as Chapman et al., ${ }^{3}$ that found levels that exceeded the score of 7 (in the Portuguese validation the cutoff score is 11 ) on anxiety (42\%) and depression (42\%) symptoms in patients with Charcot foot $(n=50)$. Furthermore, Nash, Ireland and Pearson ${ }^{49}$ revealed that, $51.7 \%$ of the 60 participants were depressed, with $17 \%$ having had a prior diagnosis of depression and 35\% had unrecognized cases of depression. Thus, anxiety and depression symptoms should not be underestimated, considered normal or temporary at pre-surgery, and a structured psychological assessment should be made in order to understand the severity of the symptoms and their interference in daily life, and to prevent the chronicity and adverse outcomes such as healing delay after LLA.

Regarding the second goal of this study, results showed that anxiety decreased significantly after surgery, regardless of the length of hospital stay, duration of ulcer and number of previous amputations, yet there were no differences in depression. There are some possible explanations for this result. The decrease in anxiety symptoms may be due to the fact that patients have found substantial relief from their fears and concerns after surgery. Also, the mean length of hospital stay in this study was 25 days, and the negative effect of prolonged hospitalization is well known and may lead to functional decline, worsening cognitive impairment and increased risks of iatrogenic injury. ${ }^{50}$ Regarding the association between anxiety and pain, it may be possible that those patients with pain at T0, after surgery, felt a decrease in pain. In fact, amputation is a life-saving event and, in patients with PAD, it significantly reduces the severity of pain. Consequently, there may be a decrease in anxiety symptoms or, given the bidirectional relationship, the opposite may also be possible. Finally, taking into

Table 2

Predictors of depression and anxiety symptoms at post-surgery (T1, n = 113).

\begin{tabular}{|c|c|c|c|c|c|c|}
\hline \multirow[t]{2}{*}{ Predictors at pre-surgery (T0) } & \multicolumn{3}{|c|}{ Depression post-surgery } & \multicolumn{3}{|c|}{ Anxiety post-surgery } \\
\hline & $B$ & SE B & Beta & $B$ & SE B & Beta \\
\hline \multicolumn{7}{|l|}{ Step 1} \\
\hline Gender (female) ${ }^{\mathrm{a}}$ & 1.009 & 1.190 & 0.078 & 1.515 & 1.173 & 0.125 \\
\hline Age (years) ${ }^{\mathrm{b}}$ & 0.119 & 0.50 & $0.225^{*}$ & 0.001 & 0.049 & 0.002 \\
\hline Type of Foot (neuropathic) ${ }^{a}$ & 0.683 & 1.363 & 0.051 & -0.608 & 1.343 & -0.049 \\
\hline Number of hospitalizations ${ }^{b}$ & 0.927 & 0.575 & 0.153 & 0.002 & 0.566 & 0.000 \\
\hline Number of complications ${ }^{\mathrm{b}}$ & 1.099 & 0.596 & 0.187 & 0.793 & 0.587 & 0.144 \\
\hline Pain $^{a}$ & 0.910 & 1.195 & 0.075 & 0.517 & 1.178 & 0.046 \\
\hline $\operatorname{adj} R^{2}$ & & & 0.10 & & & 0.02 \\
\hline$\Delta R^{2}$ & & & $0.15^{* *}$ & & & 0.52 \\
\hline \multicolumn{7}{|l|}{ Step 2} \\
\hline Gender ${ }^{\mathrm{a}}$ & -0.614 & 1.145 & -0.047 & -0.152 & 1.091 & -0.013 \\
\hline Age & 0.071 & 0.047 & 0.134 & -0.039 & 0.045 & -0.079 \\
\hline Type of Foot ${ }^{\mathrm{a}}$ & 0.427 & 1.252 & 0.032 & -0.740 & 1.193 & -0.059 \\
\hline Number of hospitalizations & 0.639 & 0.542 & 0.105 & -0.024 & 0.516 & -0.004 \\
\hline Number of complications & 0.553 & 0.584 & 0.094 & 0.421 & 0.537 & 0.077 \\
\hline Pain $^{\mathrm{a}}$ & 0.744 & 1.098 & 0.061 & 0.388 & 1.045 & 0.034 \\
\hline Anxiety $\mathrm{T}^{\mathrm{b}}$ & 0.031 & 0.106 & $0.259^{* *}$ & 0.503 & 0.101 & $0.463^{* * *}$ \\
\hline Depression $\mathrm{TO}^{\mathrm{b}}$ & 0.280 & 0.103 & $0.268^{* *}$ & 0.084 & 0.098 & 0.086 \\
\hline $\operatorname{adj} R^{2}$ & & & 0.24 & & & 0.21 \\
\hline$\Delta R^{2}$ & & & $0.15^{* * *}$ & & & $0.22^{* * *}$ \\
\hline
\end{tabular}

${ }^{*} p<0.05,{ }^{* *} p<0.01,{ }^{* * *} p<0.001$.

a Dichotomous variables yes/no.

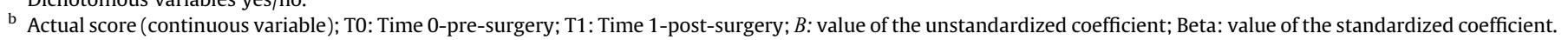


account the average duration of hospitalization, in this study, some patients remained hospitalized for almost a month after LLA. Thus, patients had not yet been confronted with the daily difficulties, whether family, social, or even individual (e.g. difficulties in selfcare), that they will face when returning home. Therefore, patients at this time may not yet be able to emotionally process the experience. However, these hypotheses should be pursued in future studies however in our view, the results emphasize the need for psychological monitoring and support of these patients in order to avoid masking premorbid symptoms and prevent negative longterm outcomes at discharge.

Finally, the last goal of this study was to find the best predictors of anxiety and depression symptoms at $\mathrm{T} 1$, in order to identify those patients at higher risk of post-surgery depression and anxiety symptoms. Thus, according to results, pre-surgery anxiety and depression emerged as predictors, over and above clinical and demographic variables, being significant positive predictors of postsurgery anxiety and depression, with patients who experienced high levels of symptoms before surgery continuing to feel anxious and depressive afterwards. However, anxiety before the surgery was the only significant predictor of anxiety after the surgery. As previous studies have shown, pre-surgery anxiety predicted more post-surgery anxiety beyond the influence of age, gender and medical variables. ${ }^{51-53}$ Contrary to other studies, where the prevalence of depression was higher in women across all age groups, ${ }^{3,54}$ in this study there were no differences according to gender. Therefore, we believe this result may be due to the small number of women in the sample $(n=52)$. With regard to the predictors of depression at T1, in the first model, age emerged as a significant predictor of depression. However, when anxiety and depression at T0, were added to the model, this predictor was no longer significant. Moreover, in both models, the presence of pain was not a significant predictor of anxiety and depression at post-surgery. Therefore, anxiety and depression symptoms at pre-surgery were the strongest predictors of anxiety and depression at post-surgery, in this sample.

This study has several implications for clinical practice. The present study identified anxiety and depression symptoms before LLA surgery as significant predictors of anxiety and depression symptoms after surgery. Thus, contrary to clinical or demographic characteristics, those variables are amenable to change before surgery through appropriate psychological interventions that may prevent adverse outcomes. Unfortunately though, symptoms of depression are more stable and more difficult to change in a brief psychological intervention during hospitalization, patients should therefore, be referred to a more structured psychological intervention. However, as anxiety and depression are interwoven, we believed that any change in anxiety levels may have an impact not only on anxiety, but also on depression symptoms. The main target of intervention should be anxiety management before surgery, since it predicted of both anxiety and depression at post-surgery. Psychological interventions that address anxiety, such as brief cognitive-behavioral therapy (e.g. relaxation training, induction of imagery through behavioral instructions, positive coping strategies), is the gold standard intervention and have been widely used in hospitalized patients. ${ }^{55,56}$ In fact, recently, a study reported that a short course of cognitive behaviour therapy was an effective and inexpensive method for reducing health anxiety among patients in medical settings. ${ }^{57}$ For those patients with minor amputations, who are having difficulty adhering to self-care foot behaviors, interventions to increase adherence to protective behaviors and promote vigilance, should be available in the hospital and rehabilitation settings, in order to avoid a more proximal amputation. Also, in the context of a multidisciplinary team, during the rehabilitation process, health professionals such as physicians, nurses, podiatrists, physical therapists and occupational therapists should be aware of the likelihood that patients may experience anxiety and depression symptoms which may be confused with diabetes symptoms (tiredness, lack of appetite, weight gain, sleep disorders). ${ }^{58}$

In this study, disability was the result of a dynamic interaction between a medical condition (lower limb amputation) and personal factors (emotional reactions before and after LLA). According to the ICF model, intervention should focus not only on medical treatment, associated with a health condition, but also on the prevention of major impairments through a rapid admission in a rehabilitation program and on the prevention of further limitations in daily activities. Given that patients' psychological status is determinant to promote positive outcomes after amputation, tailored multidisciplinary interventions need to be developed and implemented in order to prevent long-term disability. In addition, contextual factors related to patients' environment should also be addressed in future studies (e.g. presence of a caregiver, family functioning, and social support). Moreover, future studies should also focus on patients' specific fears regarding surgery that may increase preexisting anxiety levels.

However, this study has limitations that need to be acknowledged such as the small sample size and the reduced number of women included in the sample. Also, the low educational level of the sample may affect the external validity of the findings, since more educated patients could have more accurate information about surgery and therefore feel less anxiety at T0. Therefore, generalization of the conclusions should be interpreted with caution. In addition, the ICF model emphasizes a dynamic interplay between personal and environmental factors on the functioning of individuals with a health condition and/or disability, yet in this study, only some dimensions of the theoretical model was used.

\section{Conclusion}

In this study, some dimensions of the ICF model were used to enhance the knowledge about the specific relationship between a health condition and personal factors before surgery, in order to prevent unfavorable outcomes after LLA. It is important to emphasize, that LLA is a medical condition, but it is not necessarily a disability. Disability arises from the interaction of a functional limitation with one's environment. Finally, we hope this study may shed some light regarding the emotional reactions of patients before and after an amputation, emphasizing the fact that people living with chronic illness and disability are at a substantially increased risk of poor health and unhealthy behaviors. For this reason, multidisciplinary interventions are required during hospitalization, and also in the community, taking into account not only the patient's physical condition, but also the psychological, social and environmental barriers that prevent rehabilitation and reintegration into "life before amputation".

\section{Conflict of interest}

The authors declare that they have no conflict of interest.

\section{Compliance with ethical standards, human and animal rights and informed consent}

All procedures performed in studies involving human participants were in accordance with the ethical standards of the institutional and/or national research committee and with the 1964 Helsinki declaration and its later amendments or comparable ethical standards. Patients signed an informed consent. 


\section{Funding}

This study was conducted at Psychology Research Centre (PSI/ 01662), University of Minho, and supported by the Portuguese Foundation for Science and Technology and the Portuguese Ministry of Science, Technology and Higher Education through national funds and cofinanced by FEDER through COMPETE2020 under the PT2020 Partnership Agreement (POCI-01-0145-FEDER-007653). This work was supported by a grant (SFRH/BD/87704/2012) from the Portuguese Foundation for Science and Technology.

\section{Acknowledgments}

The authors gratefully acknowledge the contributions of the Multidisciplinary Diabetic Foot Clinics of the following hospitals: CHP, CHSJ, CHVNG/E, CHTS, ULSAM and the Vascular Surgery Departments in Braga and CHSJ Hospitals. The authors also wish to thank all patients who agreed to participate in this study.

\section{References}

1. Collins MM, Corcoran P, Perry IJ. Anxiety and depression symptoms in patients with diabetes. Diabet Med. 2009;26(2):153-161.

2. Khuwaja AK, Lalani S, Dhanani R, Azam IS, Rafique G, White F. Anxiety and depression among outpatients with type 2 diabetes: a multi-centre study of prevalence and associated factors. Diabetol Metab Syndr. 2010;2:72.

3. Chapman Z, Shuttleworth CMJ, Huber JW. High levels of anxiety and depression in diabetic patients with Charcot foot. J Foot Ankle Res. 2014;7:22.

4. Ikem RT, Ikem IC, Ola BA. Relationship between depression, cognitive function and quality of life of Nigerians with diabetic foot ulcers, a preliminary controlled study. Acta Endocrinol V. 2009:75-83.

5. Ismail K, Winkley K, Stahl D, Chalder T, Edmonds M. A cohort study of people with diabetes and their first foot ulcer: the role of depression on mortality. Diabetes Care. 2007;30:1473-1479.

6. Papelbaum M, Moreira R, Coutinho W, et al. Depression, glycemic control and type 2 diabetes. Diabetol Metab Syndr. 2011;3:1-17.

7. Kendzor DE, Chen M, Reininger BM, Businelle Ms, Stewart DW, Fisher-Hoch SP. The association of depression and anxiety with glycemic control among Mexican Americans with diabetes living near the U.S.-Mexico border. BMC Public Health. 2014;14:176.

8. Pandit AU, Bailey SC, Curtis LM, et al. Disease-related distress, self-care and clinical outcomes among low-income patients with diabetes. J Epidemiol Community Health. 2014;68:557-564.

9. Bell RA, Andrews JS, Arcury TA, Snively BM, Golden SL, Quandt SA. Depressive symptoms and diabetes self-management among rural older adults. Am J Health Behav. 2010;34:36-44.

10. Rivera-Hernandez M. Depression, self-esteem, diabetes care and self-care behaviors among middle-aged and older Mexicans. Diabetes Res Clin Pract. 2014;105(1):70-78.

11. Coelho CR, Zantut-Wittmann DE, Parisi MC. Cross-sectional study of depression and self-care in patients with type 2 diabetes with and without foot ulcers. Ostomy Wound Manag. 2014;60(2):46-51.

12. Gonzalez JS, Safren SA, Cagliero E, et al. Depression, self-care, and medication adherence in type 2 diabetes: relationships across the full range of symptom severity. Diabetes Care. 2007;30:2222-2227.

13. Fisher L, Skaff MM, Mullan JT, et al. Clinical depression versus distress among patients with type 2 diabetes: not just a question of semantics. Diabetes Care. 2007:30:542-548.

14. Nam S, Chesla C, Stotts NA, Kroon L, Janson SL. Barriers to diabetes management: patient and provider factors. Diabetes Res Clin Pract. 2011;93:1-9.

15. Monami M, Longo R, Desideri CM, Masotti G, Marchionni N, Mannucci E. The diabetic person beyond a foot ulcer: healing, recurrence, and depressive symptoms. J Am Podiatr Med Assoc. 2008;98:130-136.

16. Vedhara K, Miles JNV, Wetherell MA, et al. Coping style and depression influence the healing of diabetic foot ulcers: observational and mechanistic evidence. Diabetologia. 2010;53:1590-1598.

17. Tennvall GR, Apelqvist J. Health-related quality of life in patients with diabetes mellitus and foot ulcers. I Diabetes Complicat. 2000;14:235-241.

18. Carrington AL, Mawdsley SK, Morley M, Kincey J, Boulton AJ. Psychological status of diabetic people with or without lower limb disability. Diabetes Res Clin Pract. 1996;32(1-2):19-25.

19. Farah Taha MA, Lipsitz JD, Galea S, Demmer RT, Talley NJ, Goodwin RD. Anxiety disorders and risk of self-reported ulcer: a 10-year longitudinal study among US adults. General Hosp Psychiatry. 2014;36:674-679.

20. Grigsby AB, Anderson RJ, Freedland KE, Clouse RE. Prevalence of anxiety in adults with diabetes: a systematic review. J Psychosom Res. 2002;53: 1053-1060.

21. Peyrot M, Rubin R. Levels and risks of depression and anxiety symptomatology among diabetic adults. Diabetes Care. 1997;20:585-590.

22. Grieve RJ. Day surgery preoperative anxiety reduction and coping strategies. $\mathrm{Br}$ J Nurs. 2002;11:670-678.

23. Stirling L, Raab G, Alder EM, Robertson F. Randomized trial of essential oils to reduce perioperative patient anxiety: feasibility study. J Adv Nurs. 2007;60: 494-501.

24. Starkweather AR, Witek-Janusek L, Nockels RP, Peterson J, Mathews HL. Immune function, pain, and psychological stress in patients undergoing spinal surgery. Spine. 2006;31:E641-E647.

25. Portuguese Diabetes Society (PDS, 2014), Diabetes: Factos e Números 2014: Relatório Anual do Observatório Nacional da Diabetes, [Diabetes: Facts and Numbers 2014: annual report from Diabetes National Observatory], Available at: https://www.dgs.pt/estatisticas-de-saude/estatisticas-de-saude/ publicacoes/diabetes-factos-e-numeros-2014.aspx.

26. Cavanagh SR, Shin LM, Karamouz N, Rauch SL. Psychiatric and emotional sequelae of surgical amputation. Psychosomatics. 2006;47:459-464. https:// www.ncbi.nlm.nih.gov/pubmed/17116945.

27. Darnall B, Ephraim P, Wegener S, et al. Depressive symptoms and mental health service utilization among persons with limb loss: results of a national survey. Arch Phys Med Rehabil. 2005;86:650-658.

28. Livneh H, Antonak RF, Gerhardt J. Psychosocial adaptation to amputation: the role of sociodemographic variables, disability related factors and coping strategies. Int J Rehabil Res. 1999;22:21-31.

29. Schoppen T, Boonstra A, Groothoff JW, de Vries J, Goeken LN, Eisma WH. Physical, mental, and social predictors of functional outcome in unilateral lower-limb amputees. Arch Phys Med Rehabil. 2003;84:803-811.

30. Yilmaz M, Gulabi D, Kaya I, Bayram E, Cecen GS. The effect of amputation level and age on outcome: an analysis of 135 amputees. Eur J Orthop Surg Traumatol. 2016;26:107-112.

31. Singh R, Hunter J, Philip A. The rapid resolution of depression and anxiety symptoms after lower limb amputation. Clin Rehabil. 2007;21:754-759.

32. Singh R, Ripley D, Pentland B, et al. Depression and anxiety symptoms after lower limb amputation: the rise and fall. Clin Rehabil. 2009;23:281-286.

33. Machado-Vaz I, Roque V, Pimentel S, Rocha A, Duro H. Caracterização psicossocial de uma população portuguesa de amputados do membro inferior [Psychosocial characterization of a Portuguese sample of lower limb amputees]. Acta Méd Port. 2012;25:77-82.

34. Norlyk A, Martinsen B, Kjaer-Petersen K. Living with clipped wings: patients experience of losing a leg. Int J Qual Stud Health Well-being. 2013;8:10.

35. Senra H, Oliveira RA, Leal I, Vieira C. Beyond the body image: a qualitative study on how adults experience lower limb amputation. Clin Rehabil. 2011;26: $180-191$.

36. Sibbald R, Armstrong D, Orsted H. Pain in diabetic foot ulcers. Ostomy Wound Manag. 2003;49:24-29.

37. Pedras S, Carvalho R, Pereira MG. Sociodemographic and clinical characteristics of patients with diabetic foot ulcer. Rev Assoc Méd Bras. 2016;62:171-178.

38. Bengtsson L, Jonsson M, Apelqvist J. Wound-related pain is underestimated in patients with diabetic foot ulcers. J Wound Care. 2008;17:433-435.

39. Castro M, Quarantini L, Daltro C, et al. Comorbid depression and anxiety symptoms in chronic pain patients and their impact on health-related quality of life. Rev Psiquiatr Clín. 2011;38:126-129.

40. Jones J, Barr W, Robinson J, Carlisle C. Depression in patients with chronic venous ulceration. Br J Nurs. 2006;15:17-23.

41. Kiecolt-Glaser JK, Marucha PT, Malarkey WB, Mercado AM, Glaser R. Slowing of wound healing by psychological stress. Lancet. 1995;346:1194-1196.

42. World Health Organization. Towards a Common Language for Functioning, Disability and Health: ICF the International Classification of Functioning, Disability and Health; 2001. Available at: http://www.who.int/classifications/icf/training/ icfbeginnersguide.pdf.

43. Gallagher P, Donovan MA, Doyle A, Desmond D. Environmental barriers, activity limitations and participation restrictions experienced by people with major limb amputation. Prosthet Orthot Int. 2011;35(3):278-284.

44. Kohler F, Cieza A, Stucki G, et al. Developing core sets for persons following amputation based on the international classification of functioning, disability and health as a way to specify functioning. Prosthet Orthot Int. 2009;33(2): 117-129.

45. Horgan O, MacLachlan M. Psychosocial adjustment to lower limb amputation: a review. Disabil Rehabil. 2004;26:837-850.

46. Zigmond AS, Snaith RP. Hospital anxiety and depression scale. Acta Psychiatr Scand. 1983;67:361-370.

47. Pais-Ribeiro J, Silva I, Ferreira T, Martins A, Meneses R, Baltar M. Validation study of a Portuguese version of the hospital anxiety and depression scale. Psychol Health Med. 2007;12:225-237.

48. Desmond DM, Maclachlan M. The factor structure of the hospital anxiety and depression scale in older individuals with acquired amputations: a comparison of four models using confirmatory factor analysis. Int J Geriatr Psychiatry. 2005;20(4):344-349.

49. Nash T, Ireland V, Pearson S. Assessment of depression in people with diabetes attending outpatient clinics for the treatment of foot ulceration. $J$ Foot Ankle Res. 2013;6:028.

50. Monk TG, Price CC. Postoperative cognitive disorders. Curr Opin Crit Care. 2011;17:10.

51. Caumo W, Schmidt AP, Schneider CN, et al. Risk factors for postoperative anxiety in adults. Anaesthesia. 2001;56:720-728.

52. Karanci AN, Dirik G. Predictors of pre and postoperative anxiety in emergency 
surgery patients. J Psychosom Res. 2003;55:363-369.

53. Pinto P, McIntyre T, Ferrero R, Almeida A, Araújo-Soares V. Predictors of acute postsurgical pain and anxiety following primary total hip and knee arthroplasty. J Pain. 2013;14:502-515.

54. Hawamdeh ZM, Othman YS, Ibrahim AI. Assessment of anxiety and depression after lower limb amputation in Jordanian patients. I Neuropsychiatr Dis Treat. 2008;4:627-633.

55. Johnston M, Vogele C. Benefits of psychological preparation for surgery: a meta-analysis. Ann Behav Med. 1993;15(4):245-256.
56. Michie S, Johnston M, Francis J, Hardeman W, Eccles M. From theory to intervention: mapping theoretical derived behavioural determinants to behaviour change techniques. Appl Psychol. 2008;57:660-680.

57. Tyrer P, Cooper S, Salkovskis P, et al. Clinical and cost-effectiveness of cognitive behaviour therapy for health anxiety in medical patients: a multicentre randomized controlled trial. Lancet. 2014;383:219-225.

58. Egede LE, Ellis C. Diabetes and depression: global perspectives. Diabetes Res Clin Pract. 2010;87(3):302-312. 